\title{
Developing, Maintaining, and Using a Body of Knowledge for the Massage Therapy Profession
}

\author{
JoEllen M. Sefton, PhD, ATC, CMT, ${ }^{1}$ Michael Shea, PhD, LMT, ${ }^{2}$ Chip Hines, LMT, PMP ${ }^{3}$ \\ ${ }^{1}$ Department of Kinesiology, Auburn University, ${ }^{2}$ Department of Embryology, Santa Barbara Graduate Institute, \\ Santa Barbara, CA, ${ }^{3} \mathrm{C}$ Hines LLC
}

Background: The diverse field of massage therapy has lacked a formal body of knowledge to serve as a practice and educational foundation and to guide future development. This deficit has hampered the growth of the profession and its acceptance and recognition by the medical and allied health care community.

Purpose: To provide massage therapists, bodyworkers, physicians, educators, and associated allied health care professionals in the United States with a description of the purpose and development of the massage therapy body of knowledge (MTBOK) and recommendations for its future development and utilization.

Methods: Professional groups in the massage therapy community came together and established a task force to develop a body of knowledge for the profession. Five groups became the stewards for this effort. A nationwide search produced a task force of eight volunteers from diverse areas of the profession charged with the responsibility of researching and developing the MTBOK document. Review of documents, curricula, state laws and regulations, certification exam content, interviews, and public comment resulted in the development of the MTBOK. During development multiple opportunities for comment and discussion by stakeholders (public) were provided in an effort to create a professional consensus.

Results: The resulting MTBOK document establishes professional descriptions of the field; scope of practice; knowledge, skills, and abilities for entry-level massage therapists; and definitions for terminology to insure standardization, in order to provide a foundation for future discussion and growth.

Conclusions: The MTBOK fulfills the goal for which it was developed, to serve as a foundation for the growth and development of the massage therapy profession as a whole. A living document, it should continue to evolve and grow with the profession. Maintenance and continued stewardship of this document by the massage therapy community is vital for continued professional progress.
KEYWORDS: Task force, alternative and complementary medicine, massage education, scope of practice, KSAs (knowledge, skills, and abilities)

\section{INTRODUCTION}

The field of massage therapy is a diverse profession made up of a vast array of techniques and subdisciplines that share common goals and objectives for providing client/patient-centered health care and wellness that involves human touch. ${ }^{(1-7)}$ With its origins in ancient practices from around the world, massage therapy shares common roots with other bodywork and bodycentered therapies. Massage therapy practitioners have a wide variety of education, training, and experience. ${ }^{(7,8)}$ This diversity is both our greatest asset as a profession and an obstacle to the establishment of a common foundation and set of academic standards from which the massage therapy profession can grow.

The growth of massage therapy as a profession has been hindered by the lack of a formal foundational statement describing our scope of practice; educational requirements; knowledge, skills, and abilities (KSAs); and common terminology $(8,9)$ - a professional body of knowledge (BOK). A BOK can be defined as the domain of essential information, mastery over which results in the knowledge, skills and abilities necessary to practice. ${ }^{(9)}$ This lack of a BOK is an issue in areas of wellness practices, and is especially problematic for massage within the health care community. Without this foundation our profession would continue to lack full acceptance by the general population, the medical community, and other allied health care fields. ${ }^{(10)}$ Many in the massage therapy community are working to provide insurance reimbursement for our services within the heath care system, providing greater access to our services by those who cannot afford the out-ofpocket expenses. The lack of a formal, agreed-to BOK limits not only our future development, but also our ability to fully serve our clients/patients.

To solve this problem, several organizations representing massage therapists came together to begin the process of developing a massage therapy body of knowledge (MTBOK). Over several years and many 
discussions a plan emerged to generate an MTBOK document developed by and for the profession via a volunteer task force. Five organizations representing massage therapists agreed to serve as project stewards, to oversee and fund the effort without influencing the direction or the content of the final document. The purpose of this paper is to provide massage therapists, bodyworkers, physicians, educators, associated allied health care professionals, and health care insurance providers with a description of the MTBOK development process, and its intent and content; and to provide recommendations for future development and utilization of this important document.

\section{METHODS}

\section{Statement of Need}

The need for an MTBOK has been acknowledged and discussed for some time among the many associations that represent the massage therapy and allied health care professions. The vision for an MTBOK initiative was to develop and adopt a common BOK for the profession, defined as a living resource of competencies, standards, and values that inform and guide the domains of practice, licensure, certification, education, accreditation, and research.

\section{Project Organization}

Beginning in 2009, a series of meetings with representatives of the many associations relating to massage and allied health care professions were held to address shared issues (Figure 1). It was agreed that an MTBOK be developed by an independent task force composed of members of the profession, selected to represent the full massage therapy community. Five of the professional associations agreed to manage the project through stewardship (the stewards):

- American Massage Therapy Association (AMTA);

- Associated Bodywork and Massage Professionals (ABMP);

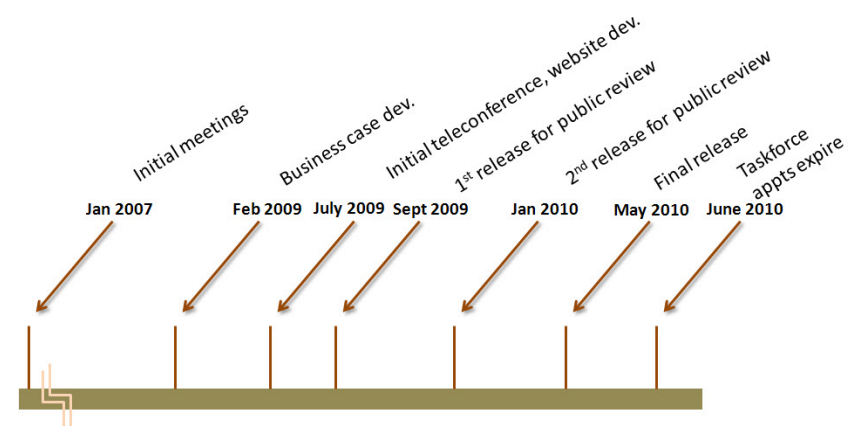

FIGURE 1. Project timeline.
- Federation of State Massage Therapy Boards (FSMTB);

- Massage Therapy Foundation (MTF);

- National Certification Board for Therapeutic Massage and Bodywork (NCBTMB).

Together these organizations (the stewards) set the general direction, and provided a framework and resources. The stewards agreed that they should not be involved in, nor have approval authority over, the content. Thus, the document was created by the shareholders (public) and not the governing organizations. ${ }^{9,11)}$ The stewards developed a business and project plan in February 2009(9) (Figure 1). A yearlong timetable was constructed, which included specific goal dates for hiring an experienced project manager; choosing eight task force members; setting first, second, and final document release dates with feedback in between the first and second release dates; and disbanding the task force.

A Project Management Institute (PMI) -certified Project Management Professional who was also a licensed massage therapist with teaching experience was hired to oversee the project and coordinate communication between the stewards and the task force members. The project manager and stewards oversaw a nationwide search for task force volunteers with the goal of including an authoritative and diverse group representative of all areas of the profession and regions of the country. Over 80 inquiries were received and 67 applicants considered by the stewards. Eight members and two alternates were chosen; all were massage therapy practitioners, and included educators, researchers, authors, school owners and administrators, continuing education providers, practitioners of advanced massage techniques, and individuals with experience working with state regulatory bodies and national certification boards.

\section{Document Development}

The project was accomplished following the principles and processes of effective project management as established by the PMI. ${ }^{(12)}$ Work was accomplished using phone conferencing (2- to 4-hour, weekly conference calls), online collaboration tools (Basecamp; 37signals, LLC, Chicago, IL, USA), and e-mail. The task force worked together for several months online and via conference calls prior to actually meeting in person for a 2-day intensive work session and presentation of the first MTBOK draft. The task force divided into two teams determined by subject specialty to facilitate development: 1) description of the field/scope of practice; and 2) practitioner KSAs. The teams completed basic research and writing, and made recommendations to the full task force for approval. Reference materials were provided by publishers for MTBOK use (Table 1). 
TABle 1. Reference Materials Provided by Publishers for the Massage Therapy Body of Knowledge (MTBOK) project

Books of Discovery

- Trail Guide to the Body, Andrew Biel

Cengage Learning

- Hydrotherapy for Health and Wellness, Richard Edison

- The Complete Spa Book for Massage Therapists, Steve Capellini

- Massage Therapy Research: What it is and How it Works, Steven Schenkman

Churchill Livingstone

- Craniosacral Rhythm, Daniel Agustoni

- Stretching Therapy, Jari Ylinen

- Clinical Applications of Neuromuscular Techniques: Practice Case Study Exercises, Leon Chaitow and Judith DeLandy

- Clinical Applications of Neuromuscular Techniques, volume 1: The Upper Body, Leon Chaitow and Judith DeLany

- Clinical Applications of Neuromuscular Techniques, volume 2: The Lower Body, Leon Chaitow and Judith DeLany

- A Myofascial Approach to Thai Massage, Howard Evans

- Manual Therapy for the Cranial Nerves, Jean-Pierre Barral and Alain Croibier

- Manual Therapy for the Peripheral Nerves, Jean-Pierre Barral and Alain Croibier

- Clinical Aromatherapy: Essential Oils in Practice, Jane Buckle

- Muscle Energy Techniques, Leon Chaitow

- Positional Release Techniques, Leon Chaitow

- Fascial and Membrane Technique: A manual for Comprehensive Treatment of the Connective Tissue Symptom, Peter Schwind

- Manual Therapy for the Peripheral Nerves, Jean-Pierre Barral and Alain Croibier

Delmar Cengage Learning

- Fascia: Clinical Applications for Health and Human Performance, Mark Lindsay

- Body Structures and Functions, Ann Scott

- Fundamentals of Anatomy \& Physiology, Donald C. Rizzo

- Theory and Practice of Therapeutic Massage, Mark F. Beck

Lippincott Williams \& Wilkins

- Pharmacology for Massage Therapy, Jean Wible

- Spa Bodywork: A Guide for Massage Therapists, Anne Williams

- Masaje Therapéutico Básico: Integración de Anatomía y Tratamiento, James H. Clay and David M. Pounds

- Massage and Manual Therapy for Orthopedic Conditions, Thomas Hendrickson

- Drug Handbook for Massage Therapists, Jean Wilde

- Stedman's Pocket Guide to Medical Language

- Teaching Massage: Fundamental Principals in Adult Education for Massage Program Instructors, John Goucher and Linda G. Francis, editors

- Review for Therapeutic Massage and Bodywork Certification, Joseph Ashton and Duke Cassel

- Pediatric Massage Therapy, Marybetts Sinclair

- Myofascial Massage, Marian Wolfe Dixon

- Plain and Simple Guide to Therapeutic and Bodywork Examinations, Laura Allen

- Hands Heal: Communication, Documentation, and Insurance Billing for Manual Therapists, Diana L. Thompson

- Hot Stone Massage: A Three-Dimensional Approach, Leslie Bruder

- The Psychology of the Body, Elliot Greene

- Muscle Pain: Understanding Its Nature, Diagnosis, and Treatments, Siegfried Mense

- Therapeutic Massage in Athletics, Pat Archer

- Anatomy: A Regional Atlas of the Human Body, Carmine D. Clemente

- Coloring: Atlas of the Human Body, Kerry L. Hull

- Massage for Orthopedic Conditions, Thomas Hendrickson

- Study Guide for Memmler's Structure and Function of the Human Body, Barbara Janson Cohen and Kerry L. Hull

- The Massage Connection: Anatomy \& Physiology, Kalyani Premkumar

- Pathology A to Z: A Handbook for Massage Therapists, Kalyani Premkumar

- Function Anatomy: Musculoskeletal Anatomy, Kinesiology, and Palpation for Manual Therapists, Christy Cael

- Nurturing Massage for Pregnancy: A Practical Guide to Bodywork for the Prenatal Cycle, Leslie Stager

- Ethics for Massage Therapists, Terrie Yardley-Nohr

- Modern Hydrotherapy for the Massage Therapist, Marybetts Sinclair

- Aromatherapy for Massage Practitioners, Ingrid Martin

- A Massage Therapist's Guide to Pathology, Ruth Werner

- Disease Handbook for Massage Therapists, Ruth Werner

- Massage Therapy Research, Tiffany Field

- Body Mechanics for Manual Therapists: A Functional Approach Self-Care, Barbara Frye

- Muscle Testing and Function with Posture and Pain, Florence Peterson Kendall and Elizabeth Kendall McCreary

- Hands Heal Essential: Documentation for Massage Therapists, Diana L. Thompson 
- Comfort Touch: Massage for the Elderly and the Ill, Mary Kathleen Rose

- Massage for the Hospital Patient and Medically Frail Client, Gayle MacDonald

- Stretching for Functional Flexibility, Phil Armiger and Michael A. Martyn

- One Year to a Successful Massage Therapy Practice, Laura Allen

- The Balanced Body: A Guide to Deep Tissue and Neuromuscular Therapy, David W. Scheumann

- Clinical Mastery in the Treatment of Myofascial Pain, Lucy Whyte Ferguson and Robert Gerwin

- Memmler's Structure and Function of the Human Body, Barbara Janson Cohen and Jason James Taylor

- Myofascial Pain and Dysfunction: The Trigger Point Manual, volume 1: Upper Half of Body, David M. Simons and Janet G. Travell

- Myofascial Pain and Dysfunction: The Trigger Point Manual, volume 2: Lower Extremities, David M. Simons and Janet G. Travell

- The Educated Heart: Professional Boundaries for Massage Therapists, Bodyworkers, and Movement Teachers, Nina McIntosh

- Therapeutic Chair Massage, Ralph R. Stevens

- Basic Clinical Therapy: Integrating Anatomy and Treatment, Clay Pounds

- Introduction to Massage Therapy, Braun Simonson

Mosby Elsevier

- Kinesiology: The Skeletal System and Muscle Function, Joseph E. Muscolino

- Mosby's Massage Therapy Review, Sandy Fritz

- The Muscular System Manual: The Skeletal Muscles of the Human Body, Joseph Muscolino

- Mosby's Fundamentals of Therapeutic Massage, Sandy Fritz

- Mosby's Essential Sciences for Therapeutic Massage, Sandy Fritz and M. James Grosenbach

- Mosby's Pathology for Massage Therapists, Susan G. Salvo

- Business and Professional Skills for Massage Therapist, Sandy Fritz

- The Muscle and Bone Palpation Manual with Trigger Points, Referral Patterns, and Stretching, Joseph E. Muscolino

- Research Methods for Message and Holistic Therapies, Glenn M. Hymel

- Sports \& Exercise Massage: Comprehensive Care in Athletes, Fitness and Rehabilitation, Sandy Fritz

- Thai Massage: A Traditional Medical Technique, Richard Gold

- Modalities for Massage and Bodywork, Elaine Stillerman

- Foundations of Manual Lymph Drainage, M. Földi and R. Strössenreuther

- Deep Tissue Massage Treatment: A Handbook of Neuromuscular Therapy, Joseph E. Muscolino

- Prenatal Massage: A Textbook of Pregnancy, Labor, and Postpartum Bodywork, Elaine Stillerman

North Atlantic Books

- Biodynamic Craniosacral Therapy, volume 1, Michael Shea

- Biodynamic Craniosacral Therapy, volume 2, Michael Shea

Pearson Prentice Hall

- Aromatherapy for Bodyworkers, Jade Shutes and Christina Weaver

- Professional Foundation for Massage Therapists, Patricia J. Benjamin

Pearson

- Tappan's Handbook for Healing Massage Techniques, Patricia J. Benjamin

- Success in Massage Therapy, Jane S. Garofano

Saunders Elsevier

- Massage Therapy: Principals and Practice, Susan G. Salvo

- Principals and Practice of Soft Tissue Manipulation, Giovanni De Domonico

Thomson Delmar Learning

- Skin Diseases: A Handbook for the Aesthetician, Pamela Hill

- Milady's Guide to Lymph Drainage Massage, Ramona Moody French

- Touch Abilities: Essential Connections, Iris Burman

- Marketing Massage: From First Job to Dream Practice, Monica Roseberry

Key aspects governing the developmental of the MTBOK are listed in Figure 2. The conceptual framework for the MTBOK was specified by the steward organizations and contains four crucial elements:

- A description of the massage therapy field;

- A scope of practice for massage therapy;

- A description of the competencies of an entrylevel massage therapist in terms of knowledge, skills, and abilities;

- Terminology specific to the massage therapy field or that has specific meanings in massage therapy.
The scope of practice team developed the description of the field and scope of practice through comprehensive online research or direct communication with state and community authorities; evaluation of all existing scope of practice statements; and review of licensing and practice laws and regulations for massage therapy in each state/ community along with any surveys or publications in this area. $(9,13-22)$

A standardized rubric for the development of a BOK was not available. The task force used standard educational practice to create a rubric by developing 


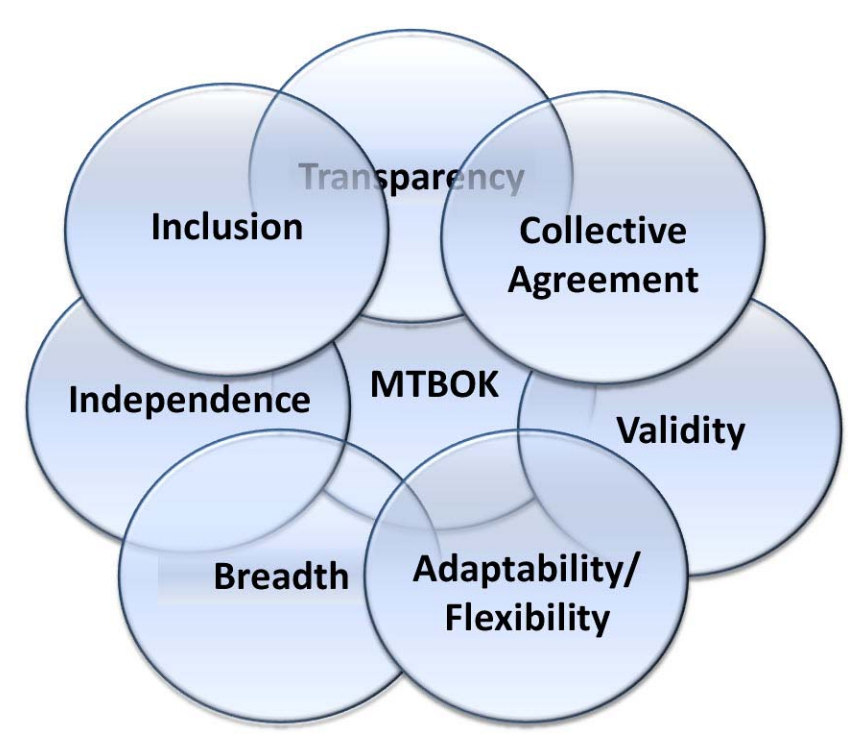

FIGURE 2. Seven governing elements for the massage therapy body of knowledge (MTBOK).

a taxonomic structure, inclusion criteria, and rating levels of importance for entry-level practitioner KSAs based on certification standards, examination content, licensure requirements, school curricula, published texts, teaching experience, safety data, and current research. ${ }^{(9,13,16-18)}$ The importance and current level of inclusion in school curricula and textbooks for each topic considered for inclusion in the KSAs was exhaustively evaluated. Final addition of a topic to the KSAs was based on a high level of importance for safe, effective, knowledgeable practice for all client/patient populations as described by current scientific knowledge. Consensus by the entire task force on each topic was required for inclusion.

Additionally, a school curriculum checklist was developed by the task force in response to multiple requests from educational institutions. The checklist is a simple summary of the categories and topics listed in the KSA portion of the MTBOK. This checklist is designed to assist individuals and institutions in evaluating current curricula or personal knowledge to determine areas for future focus. This checklist is available on the MTBOK website. (11)

\section{Evaluation}

Two cycles of public commentary during the year the document was developed resulted in comments submitted via the online survey monkey (SurveyMonkey, Palo Alta, CA, USA) comment system (Figure 3 ). Each of the comments was read and discussed, and an appropriate action was taken. A free, open stakeholder input session was held at the annual meeting of one of the steward organizations, and task force members participated in allied meetings upon request, primarily with organizations of massage educators.
These inputs into the process had a great impact on the final product.

\section{Implementation}

A first draft was formally sent to more than 14 massage and allied health field organizations for comment, publicized via press releases through two major professional associations, and made available for download in an Adobe Acrobat form on the MTBOK website ${ }^{(11)}$ for comments from all stakeholders (public). Announcements were made through e-mail lists, the stewards' organizations and associations, trade publications, and other avenues for reaching massage professionals. ${ }^{(20,22,23)}$ Other means of notifying the profession included briefings to professional associations, participation in massage-related school organizations, and a project manager's blog in order to receive maximum input by the profession and make massage professionals aware of and encourage participation in the MTBOK project.

The online surveymonkey.com comment form requested specific comments as identified by the MTBOK section and document line number, as well as general overall comments on the document. Individuals were also invited to provide an e-mail address if they wanted a personal response from the task force. More than 1200 comments were received and imported into a 373-page comment-tracking document used for review, debate, and consensus by the task force. ${ }^{(11)}$ All comments were vetted by the task force and grouped into those that were similar, those that had already been addressed by the task force, and those that were editorial in nature. This system enabled the task force members to obtain a general idea of thoughts, trends, and concerns of the stakeholders in specific areas. Additionally, comments were taken in person from September 2009 to December 2010 at six public presentations (two in Florida, and one each in Utah, Washington, Virginia, and Minnesota) and two webinars that combined to reach an additional estimated 1000 stakeholders. All comments and impressions were brought back to the task force for group discussion. (Comments may still be provided at the MTBOK website. Comments received after the final comment deadline go directly to the stewards for review and inclusion in the next review process.)

The first draft was publically presented at the first stakeholder session at the 2009 AMTA national convention. Public sessions were held for requesting organizations to encourage participation and solicit feedback from members. The second draft was released for comment in January 2010 and included all stakeholder input from draft 1 , as well as major revisions by the task force. The final MTBOK version 1.0 was publically presented at the Highlighting Massage Therapy in Complementary 


\title{
1. What Version of the MTBOK Content are you providing a comment on? (Select only ONE)
}
$\checkmark$ a. 2nd Draft, Released January 29, 2010
b. Not Related to a Specific Version

\begin{abstract}
2. Please enter your email address. Although you are not required to enter your email, it is the only way that we would
\end{abstract} be able to contact you regarding your comment.

(your email address will not be provided to others, and will only be used if necessary to contact you regarding your input)

YourEmailAddress@goes.here

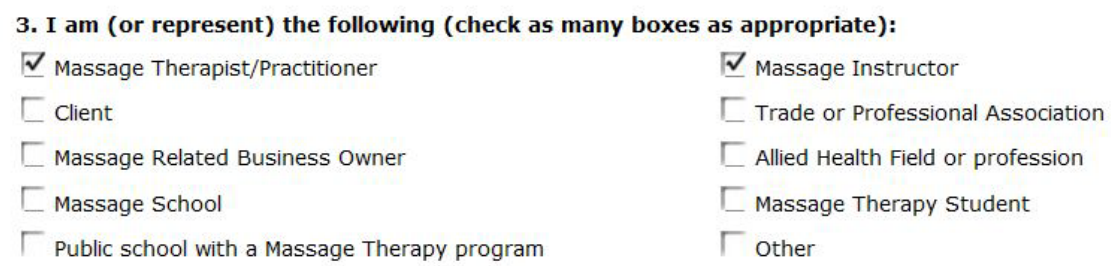

*4. What Section or category of the MTBOK is this comment about? Enter only ONE response

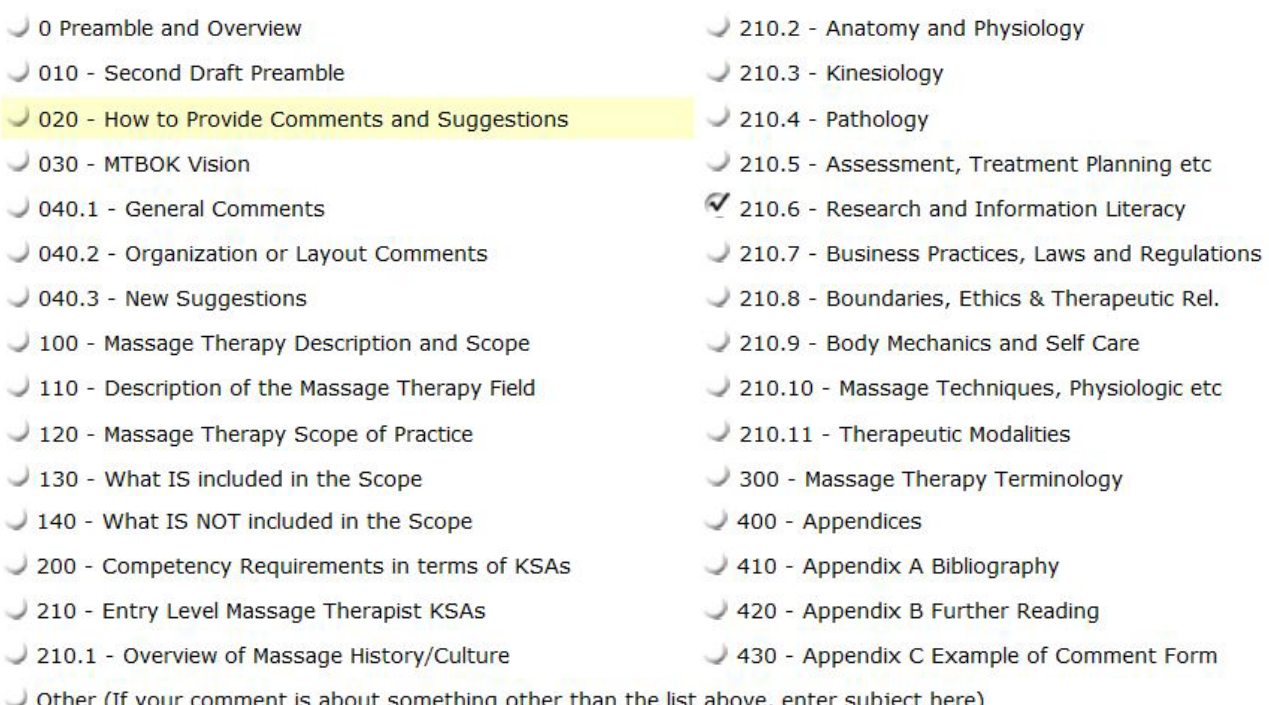

$\checkmark$ other (If your comment is about something other than the list above, enter subject here)

* 5 . What is the line number where the text you want to comment on begins? 781

* 6. Please input your comment here. (Max 20 lines of up to 100 characters each.)

Im glad to see the focus on research and information literacy here - this is very important!

Please enter only one comment per form, but enter as many forms as you would like. This makes it quick and simple for you and gives us a better way of managing the volume of comments we receive.

Thanks!

FIGURE 3. Stakeholder feedback form (completed) 
and Integrative Medicine Research Conference on May 15, 2010 and is available for download at www.mtbok.org. ${ }^{(11)}$

\section{Sustainability}

While a mechanism to update and modify the document has yet to be put into place, the MTBOK task force strongly recommends that this version $1.0^{(11)}$ be considered a living document that is regularly revised and maintained in order to fully serve a growing and changing profession. To achieve this goal volunteers from the steward organizations are collecting and reviewing comments for inclusion in the next revision. Quarterly conference calls review current activity and a face-to-face meeting of the stewards is planned for the AMTA conference in October 2011. The stewards see this time period as important for further distribution and discussion of the MTBOK. Current discussions suggest that revisions every 3-5 years may be employed.

\section{RESULTS}

The MTBOK task force developed a 58-page document that provides the profession with a foundational record outlining the scope of practice; education; entry-level KSAs; and common terminology for the massage therapy profession. ${ }^{(11)}$ With two preliminary releases each with a full round of public comment, and multiple open forums inviting comment, criticism, and discourse, the MTBOK represents the ideas and opinions of the massage profession at this time. The stewards developed seven primary elements ${ }^{(9)}$ that must be an integral part of the MTBOK project. These seven principles guided the task force at every stage of the development process (Figure 2).

1) Inclusion: The project is established by the profession and for the profession with all stakeholders participating.

2) Transparency: Communication must be maintained with all major professional stakeholders, including access at all stages of development.

3) Validity: The document must be well vetted, and must be able to continue to evolve, with commitment to ongoing review of the MTBOK.

4) Breadth: The document must be applicable across the full breadth of massage therapy.

5) Independence: The task force must be independent from the control or influence of any stakeholder group or other professional entity, and must share its results with the profession broadly, not seeking "approval" or "ratification" from any stakeholder group.

6) Adaptability/flexibility: All involved must be flexible as conditions and events change.
7) Collective agreement: The relationship of the stewards is a collective agreement; each of the organizations and its principals agreed on a framework and "ground rules" for the initiative.

The MTBOK consists of four primary content sections: Preamble and Overview; Description of Massage Therapy and Scope of Practice; Competency Requirements for a Massage Therapist in Terms of Knowledge, Skills and Abilities (KSAs); and Terminology. A summary of the content can be found in Table 2 (quotes are taken from each noted section of the MTBOK document $\left.{ }^{(11)}\right)$.

TABle 2. Summary of Massage Therapy Body of Knowledge (MTBOK) Contents

\section{Table of Contents}

Section 0 Preamble and Overview

Section 10 Preamble

Section 20 MTBOK Vision

Section 100 Description of Massage Therapy and Scope of Practice

Section 110 Description of the Massage Therapy Field

Section 120 Massage Therapy Definition and Scope of Practice Statement

Section 130 What $I s$ Included in the Scope

Section 140 What Is Not Included in the Scope

Section 200 Competency Requirements for a Massage

Therapist in Terms of Knowledge, Skills and Abilities (KSAs)

Section 210 Entry-Level Massage Therapist KSAs

Section 210.1 Overview of Massage and Bodywork History / Culture

Section 210.2 Anatomy and Physiology

Section 210.3 Kinesiology

Section 210.4 Pathology

Section 210.5 Assessment, Treatment Planning

and Documentation

Section 210.6 Research and Information Literacy

Section 210.7 Business Practices, Laws and Regulations

Section 210.8 Boundaries, Ethics and the Therapeutic

Relationship

Section 210.9 Body Mechanics and Self-Care

Section 210.10 Massage Techniques and Physiological and Psychological Effects

Section 210.11 Therapeutic Modalities

Section 300 Terminology

Section 400 Acknowledgement

Section 500 Appendix

Section 510 Appendix A: Muscle List

Bibliography 


\section{Section 0: Preamble and Overview}

This short section provides an introduction to the MTBOK document and a brief description of how and why the project came about. Here you will find an overview of what is contained and a list of some clarifications and intentions by the task force on items that have come up during the stakeholder comment process. This section also contains the vision statement for the MTBOK:

...to develop and adopt a common BOK for the profession, defined as a living resource of competencies, standards and values that inform and guide the domains of practice, licensure, certification, education, accreditation, and research.

Finally, this section reiterates the overall goal of the task force and stewards:

...that the $M T B O K$ represents the massage community and that it remains a living, learning "document," one that grows with and in some cases ahead of our community. It will remain living if you, the community, become involved with it and continue to keep it relevant, responsive, growing, and strong

\section{Section 100: Description of Massage Therapy and Scope of Practice}

This section takes on the very difficult task of defining massage therapy practice. Every profession needs a scope of practice, which is used to define what we can and cannot do as professionals. Let us be quick to point out that the MTBOK has no legal authority; this is determined by the jurisdiction in which someone practices. The scope of practice section strives to find common ground among all of the laws and statutes throughout the United States to find a common practice definition of a basically trained massage therapist. It is also noted that any additional training would expand this basic scope of practice.

\begin{abstract}
Over time, it is hoped that the MTBOK will be a source of information that legislative and regulatory bodies rely on to obtain the best information about our profession. The intention is to support legislators to make informed decisions as they formulate statutes and consider exempting from massage therapy statutes related manual practices.
\end{abstract}

This section lists examples of locations and situations in which a massage therapist might practice and techniques that may be performed by a basically trained massage therapist. Importantly, it notes techniques and treatments not included in the massage therapy scope of practice. It also notes advanced techniques that with additional training would be included in our scope of practice.

\section{Section 200: Competency Requirements for a Massage Therapist in Terms of Knowledge, Skills, and Abilities}

This section of the document provides a list of competencies that are the minimum requirements recommended by the profession for entry-level massage therapists. Each section is divided into knowledge areas (eg, anatomy), related skills (eg, locate and palpate a structure), and expected abilities (eg, recognize an endangerment site).

\begin{abstract}
A basic knowledge and understanding of these competencies is expected. These entry-level KSAs are what the profession perceives a new massage therapist would possess in order to enter into professional practice. It is presumed that these KSAs would be gained through education and training and demonstrated through examination in order to obtain license or certification for practice (dependent upon legal expectations of the jurisdiction in which they practice).
\end{abstract}

This section is designed to serve as a guide for educational institutions, continuing education providers, and practitioners to review and evaluate their own competencies, as well as areas where further programs and skills can be developed. This section can also guide researchers toward areas where evidence-based practice is lacking and additional research needs to be completed.

It is through such educational practices, as well as research endeavors, that our profession will continue to grow and advance. Through such advancement and growth, the profession will continue to inform and refine these entry-level requirements.

\section{Section 300: Terminology}

The last of the main sections is a vital component to standardizing communications within the massage therapy profession, with other allied health professions, and with massage therapy patients/clients. Too often terms can be misleading and different professions use the same term to mean different things. This serves to confuse clients and colleagues and at times cause other professions to suggest that massage therapists lack a high standard of training. A common example is the term modality. This is a common medical term defined as the method of application or the use of any physical agents and devices. In recent years this term is commonly misused to describe forms of massage (such as neuromuscular, myofascial, and Swedish massage). The misuse of common medical terms and massage terms with multiple meanings 
creates confusion and misunderstanding. The goal of this section was to

- Assist readers to develop a uniform approach to understanding the MTBOK document and any questions with which they may be concerned;

- Help to establish a common terminology to reduce any misunderstanding;

- Clarify commonly used terms felt to be misused in the field of massage therapy;

- Define those terms where there seems to be a lack of clarity on how they are being used in the field.

\section{Schools Checklist}

Additionally, it was requested during the stakeholder input sessions that the MTBOK task force develop a school curriculum checklist to assist educational institutions with program evaluation and implementation of the suggested MTBOK KSA suggestions. This checklist is a summary of the KSA competencies and is available on the MTBOK website. ${ }^{(11)}$ Individual practitioners and continuing education providers may also use this checklist for self-evaluation or to develop a continuing education plan.

Finally, this long-distance project was carried out by a nine-person team primarily through telecommunication, e-mail, and other web tools. The task force was extremely productive under compressed time lines and a very comprehensive task. The organization and structure of this project resulted in a successful effort of collaborative discourse, development, and writing that could serve as a model for additional efforts in our field and others.

\section{DISCUSSION}

\begin{abstract}
The MTBOK seeks to ensure that massage therapists are not restricted from integrating and applying knowledge and skills gained through education and certification from these practices when applying massage therapy provided they are operating within the scope of practice. The intention is to maintain the integrity of the massage therapy profession and that of related manual therapies so that we may work together respectfully for the benefit of those we touch.
\end{abstract}

The goal of this project was the development of a well-researched BOK that attempts to represent the consensus of the massage therapy profession. The MTBOK provides the massage therapy profession with foundational information on scope of practice; education; entry-level KSAs; and common terminology. ${ }^{(11)}$ With this foundation in place the profession has a basis upon which to build while still celebrating its diversity and continuing our progress as directed by the industry and government, with a common understanding of scope of practice, terminology, and important standards that make up the entry-level KSAs of the massage therapy profession.

A secondary outcome of this process was the ability of the many individuals, associations, and organizations to come together toward a common goal of furthering the profession. Inherent in the diversity of the massage therapy field is a wide array of opinions, goals, and objectives. The willingness of all to engage in open discourse and compromise throughout this process speaks to the quality and passion of those in the profession and suggests success for future joint efforts.

Several issues repeatedly arose during the stakeholder comment portion of this process that the task force and stewards have tried to clarify: ${ }^{(24)}$

1) Section design: The primary misunderstanding regarding the MTBOK has been the population discussed in the scope of practice and KSA sections. The scope of practice section was designed as a guide to practices that are appropriate for all massage therapists, with comments regarding how these practices are modified with advanced training. The KSA section is designed to be a guide strictly for entry-level massage therapists, with the understanding that those with years of experience will have a much greater knowledge base in specific areas, while possibly also needing updated training in others. In this way the KSA section can serve all domains as a self-assessment tool to guide future growth and development.

2) Legal authority: The MTBOK has no legal authority as this is held by the jurisdictions in which the massage therapist practices. If a jurisdiction provides authorization for a treatment or activity that is not listed within the MTBOK scope of practice, the therapist may legally perform that treatment or activity. It is hoped that the MTBOK will serve as a guide to lawmakers and regulators in the development of future regulations. Thus, it is important to the profession for therapists to be familiar with the MTBOK contents and provide suggestions and comments to be considered for updates.

3) Living document: The task force and stewards designed the MTBOK process to create a living document intended to change and grow with the needs of the profession. It is incumbent upon those in the profession to become involved in this process to update, refine, and correct the contents of the MTBOK to insure that it is accurate and relevant, and fully represents the needs of the massage therapy profession.

4) Leading the profession: Knowledge grows at a tremendous rate in today's society. The MTBOK is designed to be a document that informs and guides the domains of massage therapy; as such it should represent the current thinking of what 
a massage therapist should know and be able to do-without regard to what is being taught to students at the time. ${ }^{(24)}$ The MTBOK is designed to serve as a source for all professional domains (practice, licensure, certification, education, accreditation, and research) to self-assess to determine areas of success and those that could be improved. Regular updates will help to work toward professionwide consistency in performance, education, and terminology, the lack of which has been noted by other professions as a drawback in our professional development.

At the conclusion of this process the task force members wished to put forth several suggestions, some that reiterate the importance of the above information. The primary suggestion is the need for the BOK to become a "living document" that is regularly reviewed and revised. ${ }^{(11)}$ This will enable those not involved in the review process for version 1.0 to provide comment and feedback in future iterations. More important, it will enable the BOK to adapt and grow as the profession evolves. This is the only way to insure the document continues to have relevance to our development as a profession. For this to occur, a mechanism must be put in place to insure the maintenance, review, and revision of the BOK. To date no such mechanism exists; ${ }^{(10)}$ however, the stewards have put the following processes in place:

- Meet quarterly by phone and annually in person to update each other, and reexamine common intent/goals with the MTBOK;

- Collect, monitor, and respond to comments regarding the MTBOK regularly, with alternating stewards monitoring the website;

- Publish a summary of the comments every 6 months or annually, depending on the quantity or urgency;

- Regroup in approximately 3 years to begin the process of updating and revetting the document;

- Publish an updated version of the MTBOK in approximately 5 years.

The secondary suggestion of the MTBOK task force is that for this document to reach its full potential in moving the profession forward it must be utilized by all domains of the profession. ${ }^{(10)}$ It is important to understand that the BOK does not have any legal authority; however, its use to establish unified educational standards, practice acts, or licensure laws (depending which is used at a state or local level) is encouraged. To make the most of this new foundation, practitioners (including future practitioners) should see the MTBOK as a reference source for assessing their own training and planning their continuing education efforts; accreditation and certification bodies can insure that their efforts align with the document and work with the MTBOK to clarify issues; researchers can use the MTBOK to find the many areas where our research does not support practice or where knowledge is lacking; educators can use the MTBOK to evaluate current curricula and find areas lacking in content; continuing education providers now have a tool to develop new programs to meet the educational needs of existing massage therapists; and finally, licensing boards and agencies have a tool to assist in aligning their requirements with the MTBOK and other states to help ensure that any differences are either worked out or clearly identified for their constituency.

A final point from the task force is the need for additional research into the effects of massage to improve evidence-based practice in our profession. (25-31) This is vital for the profession to continue to grow and evolve, as well as for increasing acceptance in the medical and allied health care communities. With this comes the need for an improved research literacy among our practitioners. A recent article from the National Institutes of Health, National Center for Complementary and Alternative Medicine remarked on the positive outcomes reported in research on massage therapy, while also noting that there is a great deal of research still to be done. ${ }^{(32)}$ As outlined in the MTBOK, ${ }^{(11)}$ the ability to read and evaluate the research literature and adopt improved practices will be critical to improving the safety and effectiveness of the treatment massage therapists provide to patients/clients, whether this therapy is relaxation-centered spa massage or disease-based medical massage.

Possible limitations of the project include its development by a task force of eight members using the feedback obtained through the review and comment process. Every effort was made to increase practitioner involvement and encourage participation in the review process. However, it is clear that not all in the profession participated during the development of the document. Input was most likely provided by those feeling strongly about the process and those with easy computer access. While full participation is unlikely, input from as many practitioners as possible from all domains will improve the value, acceptance, and utilization of this document in the future.

In summary the MTBOK establishes professional descriptions of the field; scope of practice; KSAs for entry-level massage therapists; and standardized terminology, in order to provide a common professional foundation for future growth and development. The MTBOK is described as a living document that should continue to evolve with the growth of the profession and the supporting research. Maintenance and continued stewardship of this document by the massage therapy community as a whole is described as vital for continued professional progress. Mechanisms for use by each of the professional domains (education, research, practice, etc) are suggested 
to insure the MTBOK reaches its full potential in guiding and assisting the evolution of the massage therapy profession.

Finally, the intention is to create a common understanding of the profession. This body of knowledge will have a profound impact on the profession. The work of licensure, education, accreditation, certification, research and practice will be facilitated and the massage therapy profession will become more cohesive. In addition, the intention is that there will be a sustained interaction among all parties to keep the body of knowledge alive and growing as the profession continues to move forward.

\section{ACKNOWLEDGMENTS}

MTBOK Task Force Members: Brian Fong, Megan Lavery, Susan Salvo, Steve Schenkman, Kevin Pierce, Dawn Schmidt

\section{CONFLICT OF INTEREST NOTIFICATION}

The authors have no conflicts of interest.

\section{COPYRIGHT}

Published under the CreativeCommons AttributionNonCommercial-NoDerivs 3.0 License.

\section{REFERENCES}

1. Hertenstein MR, Holmes M, McCullough M, et al. The communication of emotion via touch. Emotion. 2009;9(4):566-573.

2. Immordino-Yang M, McColl A, Damasio H, et al. Neural correlates of admiration and compassion. Proc Natl Acad Sci US A. 2009;106(19):8021-8026.

3. Johansen-Berg H, Christensen V, Woolrich M, et al. Attention to touch modulates activity in both primary and secondary somatosensory areas. Neuroreport. 2000;11(6):1237-1241.

4. Braun MB, Simonson SJ. Introduction to Massage Therapy, 2nd edition. Philadelphia, PA: Lippincott Williams \& Wilkins; 2008.

5. Cherkin DC, Deyo RA, Sherman KJ, et al. Characteristics of licensed acupuncturists, chiropractors, massage therapists, and naturopathic physicians. J Am Board Fam Pract. 2002;15(5):378-390.

6. Field T. Massage therapy. Med Clin North Am. 2002;86(1): 163-171.

7. Sherman KJ, Cherkin DC, Kahn J, et al. A survey of training and practice patterns of massage therapists in two US states. BMC Complement Altern Med. 2005;5:13.

8. Sherman KJ, Dixon MW, Thompson D, et al. Development of a taxonomy to describe massage treatments for musculoskeletal pain. BMC Complement Altern Med. 2006;6:24.
9. Massage Therapy Body of Knowledge (MTBOK) Steward Organization. Massage Therapy Body of Knowledge (MTBOK) Business Case Summary, version 3. http://www.mtbok. org/downloads/MTBOK_Business_Case_Summary1.pdf. Published February 5, 2009. Accessed August 23, 2011.

10. Rops MS. Identifying and Using a Field's Body of Knowledge. Washington, DC: ASAE Foundation; 2002.

11. Fong B, Lavery ME, Pierce K, et al. Massage Therapy Body of Knowledge (MTBOK), version 1.0. http://www.mtbok.org/ downloads/MTBOK_Version_1.pdf. Published May 15, 2010. Accessed August 23, 2011.

12. Project Management Institute, Inc. Project Management Institute Homepage. http://www.pmi.org/. Published 2009. Updated 2011. Accessed August 23, 2011.

13. National Certification Board for Therapeutic Massage \& Bodywork (NCBTMB. http://www.ncbtmb.org/. Published 2007. Accessed 31 August 2011.

14. Associated Bodywork \& Massage Professionals (ABMP). Massage State Regulation Guide [requires login]. http://www. abmp.com/home/.

15. Philadelphia Panel. Philadelphia Panel evidence-based clinical practice guidelines on selected rehabilitation interventions for knee pain. Phys Ther. 2001;81(10):1675-1700.

16. Iowa Department of Public Health. Study for the Iowa General Assembly: Massage Therapy Modalities. Des Moines, IA: The Department; 2004.

17. Federation of State Massage Therapy Boards. Massage \& Bodywork Licensing Exam (MBLex). http://www.fsmtb.org/. Accessed 24 August 2011.

18. Massage Therapists. In: Bureau of Labor Statistics, US Department of Labor. Occupational Outlook Handbook, 2010-11 Edition. http://www.bls.gov/oco/ocos295.htm. Updated December 17, 2009. Accessed August 31, 2011.

19. National Certification Board for Therapeutic Massage \& Bodywork. National Certification Examination Candidate Handbook, version 09.1. Oakbrook Terrace, IL: The Board; 2009.

20. Osborn K. The Body of Knowledge, Massage \& Bodywork. Golden, CO: Associated Bodywork \& Massage Professionals; 2010:44-51.

21. Young LA. Massage Therapy: A Profession on the Rise. http:// www.eurekalert.org/pub_releases/2005-02/abam-mta022505.php 2007. Published February 28, 2005. Accessed August 31, 2011.

22. Schmidt DM. Defining our profession: the massage therapy body of knowledge. Massage Magazine. 2010;;175:24-30.

23. Vallet M. All for one. Massage Ther J. 2010:62-67. http:// www.amtamassage.org/articles/3/MTJ/detail/2215

24. Massage Therapy Body of Knowledge. MTBOK: past and present. http://www.mtbok.org/downloads/Past_and_Present. pdf. Published March 2011. Accessed March 2011.

25. Field TM. Massage therapy effects. Am Psychol. 1998;53(12):1270-1281.

26. Hemmings BJ. Physiological, psychological and performance effects of massage therapy in sport: a review of the literature. Phys Ther Sport. 2001;2(4):165-170.

27. Gross AR, Kay T, Hondras M, et al. Manual therapy for mechanical neck disorders: a systematic review. Man Ther. 2002;7(3):131-149.

28. Cherkin DC, Sherman KJ, Deyo RA, et al. A review of the evidence for the effectiveness, safety, and cost of acupuncture, 
massage therapy, and spinal manipulation for back pain. Ann Intern Med. 2003;138(11):898-906.

29. Moraska A. Sports massage: a comprehensive review. J Sports Med Phys Fitness. 2005;45(3):370-380.

30. Weerapong P, Hume PA, Kolt GS. The mechanisms of massage and effects on performance, muscle recovery and injury prevention. Sports Med. 2005;35(3):235-256.

31. Fernandez-de-Las-Penas C, Alonso-Blanco C, Cuadrado ML, et al. Are manual therapies effective in reducing pain from tension-type headache?: a systematic review. Clin J Pain. 2006;22(3):278-285.
32. National Center for Complementary and Alternative Medicine. Massage therapy as an option in supportive care. Complementary Altern Med Focus Res Care. 2010;Sept:1-2,4,6.

Corresponding author: JoEllen M. Sefton, 2050 Memorial Coliseum, Department of Kinesiology, Auburn University, Auburn, AL 36849, USA.

E-mail: jmsefton@auburn.edu 